\title{
Research on Personal Income Tax Affecting Structure of Resident Consumption Expenditure in China
}

\author{
Delong Zhang \\ College of Economics, Jinan University, Guangzhou, China \\ Email: 18813754319@163.com
}

How to cite this paper: Zhang, D.L. (2017) Research on Personal Income Tax Affecting Structure of Resident Consumption Expenditure in China. Modern Economy, 8, 161-171.

https://doi.org/10.4236/me.2017.82010

Received: December 21, 2016

Accepted: January 23, 2017

Published: January 26, 2017

Copyright $\odot 2017$ by author and Scientific Research Publishing Inc. This work is licensed under the Creative Commons Attribution International License (CC BY 4.0).

http://creativecommons.org/licenses/by/4.0/

\section{(c) (i) Open Access}

\begin{abstract}
The purpose of this thesis is to evaluate the impact of personal income tax on the structure of resident consumption expenditure. Food expenditure is of great importance in the consumption expenditure of residents, and it is directly related to the living standard and affluence of the residents, the author uses Engel's coefficient to conduct the corresponding analysis. This thesis is the empirical analysis of the impact of progressive index of China's personal income tax and average tax rate on food expenditure of the resident consumption expenditure. The results show that average tax rate is negatively correlated with Engel's coefficient of the seven income group residents and the integral residents. Among them, the average tax rate has the greatest impact on the consumption expenditure structure of the residents with the lowest income group, while the progressive level has no significant impact on Engel's coefficient of the seven income group residents and the integral residents. From the international horizontal comparison, too low of the average tax rate is the important factors for restricting China's personal income tax from reducing Engel's coefficient.
\end{abstract}

\section{Keywords}

Personal Income Tax, Engel's Coefficient, Average Tax Rate, Progressive Level

\section{Introduction}

Since the first taxation of personal income tax in the United Kingdom in 1799, many countries have begun to impose the personal income tax (hereinafter referred to as "personal tax"), which has currently become the main source of revenue of many developed countries, in 2012, the personal tax income in the 
OECD member countries accounted for $24.9 \%{ }^{1}$, which was only second to the social security tax and goods and services tax. China's personal income tax is introduced after the reform and opening up, and People's Republic of Personal Income Tax Law was promulgated in 1980, but there's no unified personal income tax system then.

The progressive tax rate is often used for personal tax, the higher the income the higher the taxation, which has the positive effect on the income redistribution, and thus personal tax is often one of the hot topics of the community, many scholars have made the related research on personal tax. There are two types of research on personal tax in China at present. The first type focuses on the system design of income tax and the impact of changes of income tax system on resident income distribution. The second type is to study the impact of the personal tax on individual economic behavior. The first type of research, such as Shi Ziyin [1] et al. used the data from Hubei province to make empirical analysis of the effect of income redistribution of China's personal tax and study the effect of personal tax on the redistribution of income from different sources. Liu Yuansheng et al. [2] studied the impact of the exemption amount and tax rate adjustment on resident income distribution and economic growth of China. Through the comparative study of development and evolution process of personal tax in the United States, Peng Haiyan [3] proposed the direction of perfecting China's personal tax reform, the second type of research such as $\mathrm{Yu}$ Xiancai [4] conducted a wide range of questionnaire survey, based on the survey data, they investigate the impact of personal tax on labor supply elasticity from the two aspects of tax rate and exemption amount. Wang Xin et al. [5] found through the study that the marginal propensity to consume for income increasing the exemption amount is greater than 1, and Wan Xiangyu [6] investigated the sensitivity of adjustment of China's personal tax policy through establishment of micro-simulation model, the study found that excessive exemption will expand the income distribution gap and violate the tax fairness. Liu Hua et al. [7] found that the personal income tax as a direct tax, as the tax salience is higher, has a significant negative effect on the consumption behavior of residents.

China's personal tax rate is progressive, thus it can be predicted that China's personal tax is conducive to narrowing the income gap between residents. According to Engel's law, the structure of consumption expenditure will be varied depending on the income. If there's the lower total household income, then the proportion of consumption expenditure in the purchase of food, namely, Engel's coefficient will be the higher. As the income increases, Engel's coefficient will decline accordingly; by promoting to the country, the less the country's income, namely the poorer country, Engel's coefficient will be higher, on the contrary, a country's wealth is higher, then the country's Engel's coefficient will be lower. That is to say, the personal tax will influence the proportion of the food expenditure in the structure of resident consumption expenditure through the redistribution of the resident income, namely, Engel's coefficient. However, how Chi-

${ }^{1}$ Source: OECD OLIS database. 
na's personal tax is to affect structure of structure of resident consumption expenditure? Australian economist Nana C. Kakwani [8] proved that the personal tax redistribution effect depends mainly on two aspects of the average tax rate and the progressiveness. In this thesis, the author is to discuss the impact of China's personal tax on the structure of resident consumption expenditure by starting first from the decomposition of redistribution effect of China's personal tax, and then personal tax rate and progressiveness, thus to propose the suggestions to improve the personal tax system in China.

\section{Theoretical Analysis of Personal Tax Affecting Effect of Income Redistribution}

The effect of progressive personal tax on the income and welfare distribution is called income redistributive effect. The purpose of this thesis is to break down the two aspects of income redistributive effect of China's personal tax, and then is to evaluate the impact of these two factors on consumption expenditure of resident food. Therefore, we should first decompose the income redistributive effect of personal tax. The usual practice of measuring the effect of income redistribution on taxes is to compare the pre-tax Gini coefficient with the after-tax Gini coefficient. If the result of the pre-tax Gini coefficient minus the after-tax Gini coefficient is positive, indicating that the tax contributes to the income redistribution, thereby having the positive role in reducing the income gap; if the result of pre-tax Gini coefficient deducting the after-tax Gini coefficient is negative, indicating that the tax is not conducive to income redistribution, thereby having the negative role in narrowing the income gap. This is MT index proposed by Musgrave \& Thin (1949) and used to measure the effect of tax revenue redistribution, which is calculated as formula (1):

$$
\mathrm{MT}=G-G^{*}
$$

In this formula, $G$ represents pre-tax Gini coefficient, $G^{*}$ represents after-tax Gini coefficient. If MT index is greater than zero, indicating that tax revenue can narrow the income gap, the greater the value, the effect is more significant, on the contrary, if the MT index is less than zero, indicating that the tax revenue will widen the gap.

Australian economist Nana C. Kakwani [9] decomposes MT index, and he proved that MT index can be decomposed into formula (2):

$$
\mathrm{MT}=\frac{t P}{1-t}
$$

Wherein,

$$
P=C-G
$$

In formula (3), $t$ is the average tax rate, indicating the ratio of the actual taxes paid by the taxpayers to total income, which can be easily known from the formula, $t$ is in positive correlation to MT, that is, the higher the average tax rate, the greater MT index, the increasingly significant income redistributive effect of the tax revenue. The Pindex is an index defined by Kakwani that is specifically 
for measuring progressive level of tax revenue. The positive $P$ index is a progressive tax, and the negative $P$ index is a regressive tax. It can be known from the formula that $P$ index is in positive correlation to MT index, namely the greater the progressive level $P$, the larger MT index, the tax revenue redistributive becomes more remarkable. $C$ is the index of the tax concentration rate, and its calculation method is similar to the algorithm of Gini coefficient.

It can be seen from this formula that personal tax redistributes the income through two aspects of average tax rate and progressiveness, namely, there's positive correlation between redistribution effect and average tax rate and progressiveness. In particular, when personal tax plays the income redistribution effects, both average tax rate and progressiveness are indispensable. For example, when the average tax rate is very low, the proportion of revenue can be adjusted by tax is also low, even if the progressive level is very high at this time and the income redistributive effect of tax revenue is limited, and vice versa is the same reason. In addition, the changes of the average tax rate of personal tax and progressiveness is independent of each other to some extent. In particular, the other value size is changed under the premise of one value remaining unchanged, for example, under the premise of maintaining the progressive level of the personal tax, the average tax rate is doubled, and then personal tax income will be doubled, income redistributive effect of personal tax will also increase accordingly. Similarly, maintaining the average tax rate of personal tax unchanged, the increase of the progressiveness can also enhance the income redistributive effect of personal tax. However, in order to make full use of income redistributive effect of personal tax, there's great limitation by only increasing average tax rate or enhancing progressive level.

\section{Empirical Analysis of China's Personal Income Tax on Resident Consumption Expenditure Structure}

The data of this thesis is based on the data of seven urban residents divided according to the income level of urban residents' sample survey before 2012. Since prior to 2006, China levied only the agricultural tax of the agricultural production activities of rural residents, and since China abolished the agricultural tax in 2006, the tax law provides not to levy the personal tax for residents that are engaged in production and business activities that the agricultural tax is payable, so this thesis considers only the urban resident for the study of personal tax.

\subsection{Decomposition of Income Redistributive Effect of China's Personal Income Tax}

First, the Gini coefficient (or pre-tax Gini coefficient), after-tax Gini coefficient and tax concentration rate of all annual income of urban residents is calculated according to the statistical data, and then is to calculate MT index and progressive index $P$, see result in Table 1 .

First is to analyze MT index, as can be seen from Table 1, first of all, compared to after-tax Gini coefficient $G^{\star}$, China's annual pre-tax Gini coefficient $G$ 
Table 1. MT index and progressive index $\mathrm{P}$ of China's personal index.

\begin{tabular}{|c|c|c|c|c|c|}
\hline Year & $\begin{array}{l}\text { Pre-tax Gini } \\
\text { coefficient G }\end{array}$ & $\begin{array}{c}\text { After-tax } \\
\text { Ginicoefficient } \mathrm{G}^{*}\end{array}$ & MT index & $\begin{array}{c}\text { Tax concentration } \\
\text { ratio } \mathrm{C}\end{array}$ & $\begin{array}{c}\text { Progressive } \\
\text { index P }\end{array}$ \\
\hline 1999 & 0.2322 & 0.2317 & 0.0005 & 0.6033 & 0.3711 \\
\hline 2000 & 0.2458 & 0.2440 & 0.0018 & 0.5946 & 0.3488 \\
\hline 2001 & 0.2567 & 0.2544 & 0.0023 & 0.5974 & 0.3407 \\
\hline 2002 & 0.3081 & 0.3073 & 0.0008 & 0.6542 & 0.3461 \\
\hline 2003 & 0.3169 & 0.3152 & 0.0017 & 0.6881 & 0.3712 \\
\hline 2004 & 0.3276 & 0.3231 & 0.0045 & 0.6975 & 0.3699 \\
\hline 2005 & 0.3322 & 0.3294 & 0.0028 & 0.6748 & 0.3426 \\
\hline 2006 & 0.3292 & 0.3257 & 0.0035 & 0.7235 & 0.3943 \\
\hline 2007 & 0.3249 & 0.3201 & 0.0038 & 0.7267 & 0.4018 \\
\hline 2008 & 0.3305 & 0.3282 & 0.0023 & 0.7360 & 0.4055 \\
\hline 2009 & 0.3237 & 0.3214 & 0.0023 & 0.7141 & 0.3904 \\
\hline 2010 & 0.3174 & 0.3151 & 0.0023 & 0.6918 & 0.3744 \\
\hline 2011 & 0.3183 & 0.3152 & 0.0031 & 0.6997 & 0.3814 \\
\hline 2012 & 0.3054 & 0.3030 & 0.0024 & 0.7477 & 0.4423 \\
\hline
\end{tabular}

Source: China Statistical Yearbook (1999-2012).

should be greater. In other words, annual MT index is greater than zero in average, indicating that China's personal tax has really played a role in narrowing income gap for the income redistribution. Second, from the trend of change of MT index, it can be found that MT index has showed increasingly large trend in the early stage. Finally, MT index is very small, indicating that China's personal tax is insufficient in regulation of income, the maximum is obtained in 2004, which is 0.0045 , while the United States MT index for the same period is 0.034 , which is 7.5 times to that in China.

Again is to observe the progressive index $P$, first, the annual $P$ index is positive, indicating that China's personal tax is progressive, meaning that highincome people should pay tax burden ratio higher than low-income people. Second is the longitudinal comparison of $P$ index for each year, it can be found that there's few changes in $P$ index, most of $P$ index fluctuate between 0.35 to 0.4 ; in addition, it can be seen that in January 2006, the salary deduction cost was increased by $100 \%$, which was an increase of $15.09 \%$ compared to the progressive index in previous year. In March 2008, the salary deduction cost was increased by $25 \%$, which was an increase of $0.92 \%$ compared to the progressive index of the previous year. On September 1, 2011, salary deduction cost was increased by $75 \%$, and the progressive index in 2012 was increased by $15.97 \%$ compared to that of the previous year, which can be seen that salary deduction cost has a significant impact on the progressive level. Finally was to conduct international horizontal comparison, from 1999 to 2012, the average value of Chi- 
na's progressive index $P$ was 0.3776 , while the progressive level of index $P$ in the United States in 2004 was 0.334 , indicating that the progressive level of personal tax in China has reached or even exceeded the level of that in developed countries.

Followed by is to calculate the average tax rate of China's personal tax according to per capita annual income of urban residents and the paid per capita personal tax, the formula is formula (4):

$$
\begin{aligned}
\text { average tax rate }= & \text { the paidper capita personal tax } / \\
& \text { per capita annual income of urban residents }
\end{aligned}
$$

See Table 2 for calculation results. By analyzing Table 2, first of all, the average tax rate of China's personal tax is generally increased year by year, from $0.09 \%$ in 1999 to $0.7 \%$ in 2011 , while there's a sudden and sharp decrease of the average tax rate in 2012, which will be explained later. Secondly, China's personal tax's average tax rate has been relatively low, the mean of average tax rate from 1999 to 2012 was only $0.48 \%$, in 2004, the average tax rate of China's personal tax was $0.60 \%$, while the average tax rate in the United States over the same period was up to $12.24 \%$, indicating that the scale of China's personal tax is still relatively small, and there's still some shortage in redistribution of China's personal tax compared with developed countries.

Compared with the progressiveness, there's great change of average tax rate of personal tax in China from 1999 to 2012, which in general showed an upward trend, and had a very significant stage feature, 1999-2005 was for the first stage,

Table 2. Average tax rate of China's personal tax.

\begin{tabular}{cccc}
\hline Year & $\begin{array}{c}\text { Per capita personal tax } \\
\text { (Yuan) }\end{array}$ & $\begin{array}{c}\text { Per capita annual income } \\
\text { (Yuan) }\end{array}$ & Average tax rate (\%) \\
\hline 1999 & 5.47 & 5888.77 & 0.09289 \\
2000 & 8.64 & 6295.91 & 0.13723 \\
2001 & 12.42 & 6868.88 & 0.18082 \\
2002 & 28.44 & 8177.40 & 0.34779 \\
2003 & 43.84 & 9061.22 & 0.48382 \\
2004 & 60.31 & $10,128.51$ & 0.59545 \\
2005 & 74.94 & $11,320.77$ & 0.66197 \\
2006 & 69.19 & $12,719.19$ & 0.54398 \\
2007 & 90.56 & $14,908.61$ & 0.60743 \\
2008 & 103.45 & $17,067.78$ & 0.60611 \\
2009 & 121.89 & $18,858.09$ & 0.64635 \\
2010 & 160.90 & $21,033.42$ & 0.76497 \\
2011 & 169.29 & $23,979.20$ & 0.70599 \\
2012 & 122.28 & $26,958.99$ & 0.45358 \\
\hline
\end{tabular}

Data source: China Statistical Yearbook (1999-2012). 
2006-2007 was for the second phase, and 2008-2010 was for the third phase, 2011-2012 was for the fourth phase. In the first three stages, the average tax rate is on the rise, this is because with the economic development, per capita income is rising, so the higher marginal tax rate is applicable for the resident income, and the average tax rate also will increase accordingly. In addition, during the first three stages of transition, the average tax rate showed a gradual decline, which was mainly because since January 1, 2006 (namely the second stage), the salary deduction cost had been increased from 800 Yuan to 1600 Yuan, there's also the corresponding of the tax rate, the increase of deduction cost made the average tax rate decrease from $0.66 \%$ to $0.54 \%$, with a decrease of $17.82 \%$, which was with the similar cause. From March 1, 2008, the salary deduction cost was increased from 1600 Yuan to 2000 Yuan, the direct consequence is the decline of the average tax rate, but there's the smaller adjustment of exemption amount for the time, resulting in even smaller decline of the average tax rate, which was only $0.22 \%$. In the fourth phase, the condition was a bit difference, since September 1 , 2011, since the exemption was reduced from the last four months of 2011, there's some decline in average tax rate in 2011 with little impact on the exemption decline, which was with a decrease of $7.71 \%$, and the average tax rate continued to have a decline in 2012 , with a decrease of $35.75 \%$.

It is worth noting that Verbist (2004) studied the personal tax system of 15 European countries and found that the average tax rate of personal tax is in negative correlation to progressive level, that is, the lower average tax rate of a country, the higher the progressive level, and vice versa is still established. At present, average tax rate of personal tax in China is low, but its progressiveness is higher, which is precisely in line with the above-mentioned law.

\subsection{An Empirical Analysis of the Impact of China's Personal Income Tax on Engel's Coefficient}

The purpose of this thesis is to study the impact of China's personal tax on resident consumption expenditure structure from two aspects of progressiveness and average tax rate. The structure of resident consumption expenditure is measured by Engel's coefficient. Therefore, this thesis firstly studies the relationship between the Engel's coefficient of seven income classes ${ }^{2}$ and the average tax rate and progressiveness of personal tax according to the income level.

Establishment of measurement model $1-7$, respectively:

$$
\begin{aligned}
& \text { Engel }_{1}=a_{0}+A_{1} P+A_{2} T+\varepsilon_{1} \\
& \text { Engel }_{2}=b_{0}+B_{1} P+B_{2} T+\varepsilon_{2} \\
& \text { Engel }_{3}=c_{0}+C_{1} P+C_{2} T+\varepsilon_{3} \\
& \text { Engel }_{4}=d_{0}+D_{1} P+D_{2} T+\varepsilon_{4} \\
& \text { Engel }_{5}=e_{0}+E_{1} P+E_{2} T+\varepsilon_{5}
\end{aligned}
$$

${ }^{2}$ The seven income classes divided according to the income level are the lowest income households, lower income households, medium lower income households, medium income households, medium upper income households, higher income households, the highest income households. 


$$
\begin{aligned}
& \text { Engel }_{6}=f_{0}+F_{1} P+F_{2} T+\varepsilon_{6} \\
& \text { Engel }_{7}=g_{0}+G_{1} P+G_{2} T+\varepsilon_{7}
\end{aligned}
$$

In model $1-7, P$ is progressive index, $T$ is average tax rate, Engel ${ }_{1}$ Engel ${ }_{2}$, Engel $_{3}$, Engel $_{4}$, Engel $_{5}$, Engel $_{6}$ and Engel ${ }_{7}$ respectively represent the seven income classes of Engel's coefficient, namely, the lowest income households, lower income households, medium lower households, medium income households, medium upper household, higher income households, and the highest income households.

Eviews 7.0 is used for analysis in this thesis, and the results are as shown in Table 3.

As can be seen from Table 3, the impact of explanatory variable average tax rate on Engel's coefficient of residents of the seven income groups is negative. For example, the higher the average tax rate, the lower Engel's coefficient of residents, indicating that residents use less of the income to buy food, and then the residents can use the greater proportion of income for improving the quality of life, that is to say, residents become rich. The coefficient of average tax rate of the model (1) and the model (7) is much larger than that of the other five groups. The coefficient of the average tax rate in the model (1) is -5.5 and the coefficient of average tax rate in the model (7) is -6.19 , indicating that average tax rate has larger impact on Engel's coefficient of residents of the lowest income group and the highest income group, indicating that the impact of average tax

Table 3. Results of regression analysis (grouped by income level, Engel's coefficient for

\begin{tabular}{|c|c|c|c|c|c|c|}
\hline & & Progressive & Average tax rate & $R^{2}$ & $\bar{R}^{2}$ & $F$ \\
\hline Model 1 & $\begin{array}{c}t \text { coefficient } \\
\text { value }\end{array}$ & $\begin{array}{l}-18.26 \\
-1.29\end{array}$ & $\begin{array}{c}-5.50 \\
-2.72^{\star *}\end{array}$ & 0.60 & 0.52 & $8.14^{*}$ \\
\hline Model 2 & $\begin{array}{c}t \text { coefficient } \\
\text { value }\end{array}$ & $\begin{array}{l}-10.18 \\
-0.75\end{array}$ & $\begin{array}{c}-4.05 \\
-2.07^{\star \star \star}\end{array}$ & 0.43 & 0.33 & $4.13^{\star * *}$ \\
\hline Model 3 & $\begin{array}{c}t \text { coefficient } \\
\text { value }\end{array}$ & $\begin{array}{l}-6.68 \\
-0.53\end{array}$ & $\begin{array}{c}-4.92 \\
-2.71^{* *}\end{array}$ & 0.52 & 0.43 & $5.87^{\star \star}$ \\
\hline Model 4 & $\begin{array}{c}t \text { coefficient } \\
\text { value }\end{array}$ & $\begin{array}{l}0.47 \\
0.04\end{array}$ & $\begin{array}{c}-4.44 \\
-2.95^{\star \star}\end{array}$ & 0.50 & 0.41 & $5.60^{\star *}$ \\
\hline Model 5 & $\begin{array}{c}t \text { coefficient } \\
\text { value }\end{array}$ & $\begin{array}{l}-0.79 \\
-0.07\end{array}$ & $\begin{array}{c}-3.54 \\
-2.33^{\star *}\end{array}$ & 0.40 & 0.30 & $3.66^{* * *}$ \\
\hline Model 6 & $\begin{array}{c}t \text { coefficient } \\
\text { value }\end{array}$ & $\begin{array}{l}-7.68 \\
-0.72\end{array}$ & $\begin{array}{c}-3.49 \\
-2.30^{\star *}\end{array}$ & 0.47 & 0.37 & $4.85^{\star *}$ \\
\hline Model 7 & $\begin{array}{c}t \text { coefficient } \\
\text { value }\end{array}$ & $\begin{array}{l}-12.23 \\
-1.06\end{array}$ & $\begin{array}{l}-6.19 \\
-3.76^{*}\end{array}$ & 0.69 & 0.64 & $12.50^{*}$ \\
\hline
\end{tabular}
residents is the explained variables).

Description: ${ }^{*}$ indicates significance at the extent of $1 \%,{ }^{* *}$ indicates significance at the extent of $5 \%,{ }^{* *}$ indicates significance at the extent of $10 \%$. 
rate on Engel's coefficient of the resident groups with the lowest income and the highest income is larger, and the impact on Engel's coefficient of residents of other five groups is more limited. In addition, there's no significant impact on the progressive level of the remaining explanatory variables.

Next, this thesis is to study the relationship between the Engel's coefficient of integral urban residents, average tax rate and progressiveness of personal tax.

Building Model 8:

$$
\text { Engel }_{0}=a_{0}+A_{1} P+A_{2} T+\mathcal{E}
$$

In model 8, $P$ is progressive index, $T$ is the average tax rate, and Engel ${ }_{0}$ is the Engel's coefficient of the integral urban residents.

In this thesis, Eviews 7.0 is used for analysis, and the results are as shown in Table 4.

It can be seen from Table 4 that when investigating the relationship between Engel's coefficient of the integral urban residents and the average tax rate and progressiveness of personal tax, it can be found that the impact of the explained variable average tax rate on Engel's coefficient of the integral residents is also significantly negative, and the impact of the explained variable progressive level on Engel's coefficient of the integral residents is not significant. In terms of coefficients, the coefficient of the logarithm variable of average tax rate logarithm is negative, indicating a negative correlation between the average tax rate and Engel's coefficient. Engel's coefficient will have a decrease of $6.02 \%$ per increase of average tax rate by $1 \%$.

Therefore, in terms of reducing Engel's coefficient of residents, and improving the affluence of residents, the role of improving average tax rate is more significant than that of progressive level, and the affluence of the resident groups with the lowest income and the highest income has more obvious improvement compared to residents of other five groups.

\section{Conclusions and Policy Recommendations}

Based on the data of urban residents' living samples conducted by National Bureau of Statistics from 1999 to 2012, this thesis analyzes the impact of China's personal tax on resident consumption expenditure structure from average tax rate and progressive level, and finding that China's personal tax has played an important role in narrowing the income gap, but the effect is not significant. It can be known from Equation (2) that the income redistribution effect of personal

Table 4. Results of regression analysis (Engel's coefficient for urban residents is the explained variable).

\begin{tabular}{cccccc}
\hline Variable & Progressive level & Average tax rate & $R^{2}$ & $\bar{R}^{2}$ & $F$ \\
\hline Coefficient & -4.60 & -6.02 & & & \\
$t$ value & -0.42 & $-3.82^{*}$ & 0.66 & 0.60 & $10.65^{\star}$ \\
\hline
\end{tabular}

Description: ${ }^{*}$ indicates significance at the extent of $1 \%,{ }^{* *}$ indicates significance at the extent of $5 \%,{ }^{* *}$ indicates significance at the extent of $10 \%$. 
tax is positively related to average tax rate and progressive level. By comparing China's personal tax system with that of the United States, it can be found that the progressive level of China's personal tax is slightly higher than that of the United States, but the average tax rate is much lower than the United States, indicating that too low average tax rate is the main cause impeding China's personal tax redistribution.

The too low of average tax rate of China's personal tax is largely due to the not perfect tax collection and management system, and a lot of taxable income is difficult to be monitored, the loss of tax is extremely serious. In China, the proportion of the actual taxpayer of the personal tax is too low compared to the total population. The research institution o Ministry of Finance (2009) indicated that in 2008, the number of China's total annual income of more than 120,000 yuan that should be the self-declaration to pay personal tax was of about 2.4 million people, accounting for about $3 \%$ of the total taxpayers of the national personal taxpayers. By calculating in this way, there were about 80 million taxpayers in China that should pay the personal tax, accounting for only about $6 \%$ of China's total population. According to the IMF report, the ratio of taxpayers of personal tax in the industrialized countries in the early 1980 s was about $46.17 \%$ on average compared to all the population, which was even higher in some countries, such as the ratio of Danish taxpayers of personal tax to total population was up to $77.80 \%$. In addition, according to the income statistics of the United States Bureau, in 2007 the taxpayers in the United States to declare personal tax were about 143 million, according to the calculation of 300 million people in the United States, then about $50 \%$ of US citizens declared personal tax.

The regression results show that the average tax rate of personal tax is negatively related to Engel's coefficient of the residents of seven income groups and the integral urban residents. The average tax rate has the greatest impact on Engel's coefficient of the resident groups with the lowest income and the highest income, the impact of progressive level on Engel's coefficient of residents of seven income groups and integral residents is not significant. Engel's coefficient is usually used to measure the affluence, that is to say, the average tax rate of China's personal tax has a great impact on the affluence of the residents.

The conclusion of this thesis is with the strong policy significance. The increase of the average tax rate of personal tax and reduce the proportion of food expenditure of residents is indispensable for improving the quality of life of residents, improving the affluence of residents, but this is also a trend. From the perspective of development trend of tax structure, it is the basic direction for the future reform of China's tax system to reduce the tax rate of value-added tax, business tax and other indirect taxes, and enhance the tax system in China. Although the three times of adjustment of personal tax conducted on January 1, 2006, March 1, 2008 and September 1, 2011 has improved progressiveness of China's personal tax, but this has made the decline in the average tax rate, which is contrary to general direction of China's tax reform. The contents of these three reforms include raising the standard for the salary deduction cost, usually 
the rise in the salary deduction cost increases the progressiveness of personal income tax while reducing average effective tax rate. However, it is one of the most important reasons by narrowing the gap between the rich and the poor, and increasing the affluence of the residents. If this is not the case, then the requirements of the standards for increasing the salary deduction cost will completely lose its rationality.

\section{References}

[1] Shi, Z.Y. and Zhang, Y.H. (2012) Progressive and Redistributive Effects of Personal Income Tax: A Case Study of Hubei Province. Finance and Economics, 3, 116-124.

[2] Liu, Y.S., Yang, C.Y. and Yuan, Q. (2013) Income Distribution Effect of Personal Income Tax. Economic Research, 1, 99-109.

[3] Peng, H.Y. (2014) Comparison between Redistributive Effects of China's Personal Income Tax with Its International Situation. East China Economic Management, 11, 63-66.

[4] Yu, X.C. (2006) Empirical Study on the Effect of Income Tax on Labor Supply. Management of World, 11, 28-40.

[5] Wang, X. and Wu, B.Z. (2011) Impact of Changes of Threshold on Levying Personal Income Tax on Consumption. World Economics, 11, 66-86.

[6] Wan, X.Y. (2011) Sensitivity Analysis of Personal Income Tax Reform: Based on Micro-Simulation Approach. World Economy, 1, 93-106.

[7] Liu, H., Chen, L.P. and Xu, J.B. (2015) The Effect of Tax Salience on Consumer Behavior. Public Finance and Taxation Forum, 3, 22-27.

[8] Musgrave, R.A. and Thin, T. (1949) Income Tax Progression 1929-48. Journal of Political Economy, 56, 98-514.

[9] Kakwani, N. (1984) On the Measurement of Tax Progressivity and Redistribution Effect of Taxes with Applications to Horizontal and Vertical Equity. Advances in Econometrics, 3, 149-168.

Submit or recommend next manuscript to SCIRP and we will provide best service for you:

Accepting pre-submission inquiries through Email, Facebook, LinkedIn, Twitter, etc. A wide selection of journals (inclusive of 9 subjects, more than 200 journals)

Providing 24-hour high-quality service

User-friendly online submission system

Fair and swift peer-review system

Efficient typesetting and proofreading procedure

Display of the result of downloads and visits, as well as the number of cited articles

Maximum dissemination of your research work

Submit your manuscript at: http://papersubmission.scirp.org/

Or contact me@scirp.org 